\title{
Narrative and gender as mutually constituted meaning-making systems
}

\author{
Robyn Fivush ${ }^{1}$ and Azriel Grysman ${ }^{2}$ \\ ${ }^{1}$ Institute for the Liberal Arts, Emory University, Atlanta, GA, USA and ${ }^{2}$ Dickinson College, \\ Carlisle, PA, USA \\ Corresponding author: Robyn Fivush, email: psyrf@emory.edu
}

\begin{abstract}
Both gender and narrative are foundational to the ways in which humans engage in meaningmaking. Arguing from evolutionary, psychological and feminist theoretical perspectives, we posit that narratives and gender are culturally mediated mutually constituted meaning-making systems: Narratives are defined through gender and gender is defined through narrative. To contextualise this argument, we define 'narrative' and 'gender' and review the extant literature on how gender is expressed in culturally mediated master narratives and how narratives are performed differently by women and men. Our core argument is that the very act of narrating is a gendered activity that constructs, represents and narrates gender as a primary category of human existence, and these fundamentally gendered ways of narrating then construct, define and reify gendered ways of being in the world.
\end{abstract}

Keywords: Narrative; Gender; Master narrative; Meaning-making

In this article, we argue that narrative and gender are core components of creating meaning in human lives, and, perhaps more provocatively, that narratives and gender are mutually constituted meaning-making systems: Narratives are defined through gender and gender is defined through narrative. We base this argument on current evolutionary (Boyd 2018), psychological (Martin and Slepian 2020) and feminist (Fivush 2004, 2010) theories. To foreshadow, we will argue that narratives and narrating serve a basic social-relational function in human evolution and culture; they communicate emotional experiences and bond groups together in advantageous ways (Donald 1993), and that, although this evolutionary advantage is, itself, not gendered, the forms and functions of narrating emerged from gendered ways of being in the world and contribute to the expression and reification of gender. In order to make our arguments, we first better specify what we mean by 'narrative' and 'gender' and how each of these terms are culturally and historically dynamic, and iteratively defined through interactions between cultural media and individual lives. We then review the research on gender and narrative to lay the foundation for our argument. In the last section, we bring the research together to show that gender and narratives are both evolving and co-constructed meaning systems. Our core argument is that the very act of narrating is a gendered activity that constructs,

(c) The Author(s), 2021. Published by Cambridge University Press. This is an Open Access article, distributed under the terms of the Creative Commons Attribution licence (http://creativecommons.org/licenses/by/4.0/), which permits unrestricted re-use, distribution and reproduction, provided the original article is properly cited. 
represents and narrates gender as a culturally mediated primary category of human existence, and these fundamentally gendered ways of narrating then construct, define and reify gendered ways of being in the world.

\section{Narrative as a core component of meaning-making}

Narrative is both the fundamental way in which individuals understand their own personal experiences, and a foundational framing of human ways of world-making (Goodman 1978). The 'narrative turn' represents a critical transition in understanding human behaviour in terms of narrative meaning-making. In the period from 1975 through 1990, across multiple disciplines, including history, anthropology, sociology, philosophy, education and the humanities, theorists argued that narratives undergird the ways in which humans process and understand lived experience (see Monteagudo 2011, for a review). Within psychology, this view was initially presented by Sarbin (1986), who argued that narrative was the root metaphor for all of psychology. Narrative theory and method have been adopted across multiple subdisciplines within psychology, including cognitive (Bruner 1991), personality (McAdams 1992) and clinical (Carr 1998). A narrative approach understands individual lives as constructed within, against and in concert with culturally canonical narratives of what a life is and how a life should be lived.

Master narratives emerge from myriad individual narratives of specific lived experiences that evolve into canonical narrative frameworks that provide culturally mediated shared understandings of the forms and functions of particular kinds of experiences across generations (Hammack 2011; McLean and Syed 2015; Merrill and Fivush 2016). In our ancestral past, culturally mediated narratives were created through in-person storytelling communities (Donald 1993), but over historical time, and especially with more current abilities to develop large shared cultural platforms through print, visual and social media, these culturally mediated narratives become both more broadly shared and more diverse (McLean and Breen 2015). In this way, canonical master narratives and personal narratives are the pivot point where culture and the individual intersect to create shared meaning (McLean and Syed 2015). Culturally mediated master narratives, embedded in the everyday media that surrounds us, infiltrate individual personal meaning-making, and the ways in which individual personal narratives are told infiltrate and shape the evolving master narratives (Breen et al 2017; McLean and Breen 2015). In sculpting narratives from the flow of experience, humans carve their lives into beginnings, middles and ends in ways that make sense of selves, others and the world (Ricoeur 1980), and the culturally mediated master narratives within which individual lives are embedded both shape and are shaped by these individual narratives (McAdams 2019).

Given the significance of narrative, it is perhaps surprising that an exact definition of narrative remains controversial; however, there is broad agreement across disciplines that narratives involve actions unfolding over time, and most agree that a complete narrative must also include at least an implicit form of evaluation of those actions (Abbot 2008; Bruner 1991; Labov 1982). A temporal arc is definitional and distinguishes narrative from other forms of cognitive and linguistic structures such as descriptions, expositions and stereotypes. These various structures, while often evaluative, do not imply temporal movement. Master narratives directly express the canonical ways in which events are expected to unfold over time. For example, McAdams (2004) has demonstrated that one of the guiding master narratives in US culture is the redemption narrative. This narrative embodies the stereotypes of being resilient and autonomous, but the narrative adds the temporal arc of moving from a negative to a positive outcome; temporal movement is the defining feature of a redemption narrative. 
Master narratives pervade our shared cultural knowledge, from fairy tales and romcoms to trauma and tragedy, through multiple media, from storytelling within families to culturally shared textual and visual platforms. These culturally canonical narrative arcs become the way in which we each story our own experiences (Thorstad et al in prep). Although not all human meaning must be temporally extended, we posit that a full sense of human meaning and purpose requires temporal extension - coherence across time in a life lived (Martela and Steger 2016; McAdams 2001) - and this is expressed through culturally canonical narratives that define both shared and individual meaning emerging over time.

\section{Gender as a core component of meaning-making}

The second part of our argument is that gender is also foundational to human meaningmaking; gender is ubiquitous across evolutionary history and cultures, and undergirds our basic conceptualizations of the world (Martin and Slepian 2020; Wood and Eagly 2012). Although notions of gender may differ across history and culture, all known human cultures make gender distinctions (Ellemers 2018; Martin and Slepian 2020). Gender is a complex construction of the dynamic and fluctuating interactions of biological sex, developmental factors and sociohistorical cultural meaning systems that create evolving meanings over individual and historical time (Wood and Eagly 2012). Within psychology, gender is usually theorised through stereotypes (Ellemers 2018). Stereotypes are hierarchically or schematically organised conceptual structures (Tao and Chen 2017) that convey expectations for gendered behaviours, roles, activities and appearances. Narratives provide additional layers of culturally mediated knowledge about how events are experienced through time as lives unfold, and this, too, is gendered. More specifically, master narratives of gender provide narrative templates or frameworks for defining gender, and gendered ways of narrating are the implicit forms and functions by which narratives express and reify gender.

Although these cultural constructions have roots in our biological and evolutionary history, it is important to note that lived experiences of gender fluctuate in sociocultural historical contexts. Yet the ways in which gender as a cultural category is constructed as a canonical narrative still expresses gender in binary, heteronormative and essentialist ways (Payne and Smith 2016). Popular media, in the form of fiction, television programmes and advertisements, continue to depict highly stereotyped and binary portrayals of gender in line with traditional gender stereotypes of men as agentic and powerful and women as passive, relationally oriented, and powerless, although these media portrayals have remained more consistent over time for roles within the family than within the workforce (Goodall 2012; Scarborugh et al 2019). Still, whereas these broad, culturally mediated master narratives provide frameworks for making sense of individual lived experience, personal narratives of individual lived experiences continue to bend and modify the evolving master narratives, and this, too, is reflected in media representations. For example, analyses of self-portrayals on Instagram, a highly popular social media site for displays of one's self and one's activities, includes women portraying themselves as independent and agentic world-travelers (Vida et al 2020). Yet, close analysis of young women's Instagram's posts continues to indicate that women use traditional female display categories, such as feminine touch, sparse clothing and withdrawing gaze, even as they portray themselves engaging in independent activities (Butkowski et al 2020; Doring et al 2016). Thus, there is evidence of both the replication of traditional gender stereotypes alongside a changing sense of gender. Indeed, the notion of gender as binary is being challenged on many social media sites; for example, a Reddit community of individuals who identify as non-binary has both increased in size and in positive 
self-portrayals over the last several years, changing the conversation about gender in the larger social media community (Darwin 2017). It is within these culturally mediated canonical master narratives about gender that individuals narrate their own lived experience in negotiated, and sometimes contested, ways, and, indeed, it is through these contested narratives that the culturally mediated master narrative may begin to bend (Gosling 2018).

\section{Master narratives of gender}

Master narratives of gender explicitly create stereotyped gendered life expectations. Motherhood is perhaps the classic example of the gendered master narrative that portrays motherhood as definitional to being a woman (Arendell 2000; Miller 2005); women who are not able to have children are pitied and women who choose not to have children are either selfish or, worse, not seen as 'real women' (Ashburn-Nardo 2017; Gotlib 2016). The master narrative goes beyond the fact of motherhood to narrate the 'good mother' in terms of how pregnancy, childbirth and childrearing unfold in harmony, affection, nurturance and pure joy (Kerrick and Henry 2017). Deviations from this master narrative are seen in fairly harsh ways, not just by others but by mothers themselves who feel they are not 'living up to' the master narrative (Miller 2005).

Other master narratives of gender define appropriate social and sexual relationships both within and across genders. For example, events that are assumed to be part of the typical life course, such as meeting and committing to a romantic partner, are gendered in the particulars of how these events stereotypically unfold differently for women and men (Ottsen and Berntsen 2014). Even non-gender specific life experiences, such as personal challenges or turning points, are expressed in gendered stereotyped ways; for example, challenging experiences are resolved through personal strength and autonomy for males but through communal caring and relationships for females (Thorne and McLean 2003), sad experiences are resolved through apologies and re-establishing the relationship for females, but not so much for males (Adams et al 1995), and women who are highly successful in stereotypically male professions provide narratives that contextualise their professional lives in terms of family relationships and obligations (Van De Mieroop et al 2017).

Looking more specifically at knowledge versus endorsement of master narratives of gender, McLean et al (2017) identified the traditional and equality master narratives, with the former reifying women's roles as caregivers and the latter emphasising equal roles and opportunities. The traditional narrative was only moderately more endorsed by college men than women for themselves, but emerging adults of both genders perceived their parents to more commonly endorse traditional gendered expectations around motherhood and caregiving. This may represent sociohistorical change, although this finding might also be a function of developmental stage, as research shows that both men and women become more gender typical with age and parenthood (Endendijk et al 2018). In line with this interpretation, when asked to rate the importance of certain life events for a person of their own gender, men rated career-related events as more centrally important than did women. Similarly, Rogers (2020) found in structured interviews that 7- to 12-year-old children mostly endorsed traditional narratives of gender, but simultaneously expressed counter or alternative narratives, suggesting that children are struggling with culturally canonical and alternative narratives of gender and, possibly, even that social and historical changes may be influencing evolving master narratives of gender in multiple ways.

Suggestions that individuals both struggle with and challenge master narratives of gender are echoed in findings collected from sexual minority youth - whereas we see new 
counter and alternative narratives arising, they are grounded in heteronormative narratives about sexuality (Hammack et al 2009). Similarly, when gender intersects with other master narratives, such as about race and age, the ways in which personal stories are told are set in concert with, or in contrast to, culturally canonical gendered master narratives (Rogers 2020; Salisu and Dacus 2021). Critically, across studies the alternative and counternarratives reference the traditional master narratives of gender in ways that suggest that these master narratives are still definitional for how one constructs their own story. Indeed, many individuals express psychological distress when countering existing master narratives of gender (McLean et al 2018). Thus, although it does seem that master narratives that define gender and gendered lives are evolving to be more fluid, culturally canonical traditional master narratives of gender continue to impose certain ways of constructing gender in individual life narratives.

\section{Performing gender in narratives}

Whereas master narratives that define gender are quite explicit, extending stereotyped roles, activities and behaviours into temporally extended gendered life narratives, more implicit gendered ways of being in the world are communicated through the very process or telling of narratives. This more subtle way of expressing gender does not define gender as a category, but rather as a way of performing. In making this argument, we draw on West and Zimmerman's (1987) 'doing gender' arguments, that explicate gender as a way of performing in the world; simply by behaving in particular ways through language and actions, we create and recreate gender in everyday interactions and, in so doing, gender becomes embedded in our everyday lives in almost invisible ways. 'Doing gender' in narrative is illustrated in both the frequency and functions of narrating and the content of narratives told.

\section{Narrating is gendered: frequency and function}

Narratives are dynamic, fluid linguistic constructions; we share the events of our lives on a daily basis with others, and ruminate and reflect on our experiences in quiet moments alone. More than $60 \%$ of our daily experiences recorded in diaries have been discussed with others during the day (Pasupathi et al 2009), and up to $90 \%$ of even mildly emotional experiences are disclosed within 48 hours (Rime 2007). Over a typical family dinner table, narratives about the day and about shared family history emerge every 5 minutes (Bohanek et al 2009). Clearly, we tell narratives. And these tellings differ by gender.

Broadly speaking, research has established gender differences in how men and women talk, both the content and the style. Using both big data analyses of extremely large databases of language use (Newman et al 2008; Schwartz et al 2013), and close qualitative study of conversations (Bischoping 1993; Burleson 2003; Tannen 2003), research indicates that women use more affiliative language than men (e.g., language aimed at creating connections with others) and men use more assertive language than women (e.g., language aimed at declaring knowledge) (Leaper and Ayres 2007). Affiliative talk can be expressed through tag questions that bring the listener along (e.g., 'isn't it?' and 'you know?'), as well as 'hedges' to indicate a softening of strong opinions (e.g., 'I think' and 'I'm not sure, but ...'). Furthermore, women talk more about other people and relationships than men do, and men talk more about sports, personal achievements and work than women do (Bischoping 1993; Schwartz et al 2013). These broad differences in language use have been interpreted as gender differences in the functions that language serves. Women use language to create relationships, interpersonal connection and emotional understanding, whereas men use language for instrumental purposes and to assert autonomy and 
achievements (Holmes 1992; Tannen 2003). Of course, like all gender differences in cognition and behaviour, these represent small differences across large groups and there is high variability within as well as across gender groups. Our arguments rely more on how gender is constructed and conceptualised through these activities and behaviours rather than on demonstrating gender differences per se.

Most important for our argument, whereas these gender differences are found across studies, it is also the case that the differences are highly context-sensitive. For example, there are no overall differences in how much women and men talk, but in certain contexts such as the home, women talk more than men, and in other contexts, such as work, men talk more than women (McGeorge et al 2004). That gender differences in language use are context-sensitive suggest that women and men may be using language for different purposes in different contexts. Context, itself, is a complex construct, as it can refer to multiple aspects of interaction. Often context refers to the location in which language is being used (e.g., workplace versus home), but language context can also refer to the linguistic forms required to participate in a particular context; for example, contexts that require small talk, formal presentations, adult-child interactions, dyads versus groups or, as we will focus on, narratives. Narratives are a type of linguistic contextual interaction in which the participants are called upon to share their own lived experience either with others who have shared those experiences, or to others to connect, inform or persuade (Hammack 2011).

Research indicates that gender differences regularly occur within narrative contexts. At the most non-controversial level, we know that women simply engage in narrating more frequently and more elaborately than do men (Grysman and Hudson 2013). Similarly, more girls and women keep personal diaries than boys and men, suggesting even when reflecting in private, women are more likely to record the experiences of their lives than are men (Harbus 2011). Self-report data indicates that women engage in more reminiscing about personal past experiences than men, and women further report using reminiscing to build intimacy to a greater extent than do men (Bluck and Alea 2002, 2009). In a study of typical family dinnertime conversations (Merrill et al 2015), there were no differences in amount of talk among mothers, fathers, daughters and sons when discussing world events and knowledge (e.g., discussing the new space program), neighbourhood activities (e.g., the new strip mall on Broadway) or regulating behaviours (e.g., please pass the salt). But for narrative talk, which accounted for about a third of all dinnertime talk, gender differences emerged. When narrating about the day's activities, the shared family past and extended family history, mothers contributed significantly more to the ongoing narratives than did fathers and children, and daughters contributed significantly more than sons. Across studies, then, women engage in more narrative talk, and perhaps use narratives to build and maintain emotional relationships and affiliations more so than men.

\section{Narratives are gendered: content}

In addition to frequency and function, the content of narratives also differs by gender. We focus specifically on themes of agency and communion, and on emotional expressions, as these are the two most prevalent stereotypes about gender, with women being considered more communal and emotional than men, and, to a lesser extent, men considered being more agentic than women (Eagly et al 2020; Ellemers 2018; Martin and Slepian 2020), and these are also differences rooted in evolutionary and biosocial theories of gender (Buss and Schmitt 2011; Wood and Eagly 2012).

Themes of agency and communion in personal narratives are theorised to stem from underlying motivational axes that undergird all human behaviour (Bakan 1966). Agency 
has been less commonly identified in narratives, but some studies have found that, compared to women, men more commonly include expressions of agency in their narratives (Boytos et al 2020; Niedzwienska 2003) and indicate agency to be more important to a sense of self (Walls et al 2001). In contrast, women narrate with more expressions of communion than men (Grysman 2018; Grysman et al 2016). Although Boytos et al (2020) reported that gender differences in agency were moderated by self-reported feminism, and Grysman et al $(2016,2017)$ reported that some variance in narrative expressions of communion was explained by self-reported endorsement of feminine-typical traits, all three studies found that a main effect of biological sex remained even when accounting for these factors (but see Compère et al 2021). In addition, these gendered themes of agency and communion find expression in social media use, as catalogued in big-data studies of language content in Facebook posts (Park et al 2016; Schwartz et al 2013). We take these findings as an indication that, although individual differences are reflected in the degree to which these motivational factors are incorporated into one's personal narratives, master narratives that define women as more communal and men as more agentic make their way into women's and men's narratives regardless of individual differences in gender identity and/or ascription to stereotypical gender roles.

Another way in which communal themes are expressed in narratives is the extent to which people and relationships are integrated into the narrative. Personal narratives can focus only on oneself, on individual autonomous actions and achievements, or on the roles of others and on relationships in one's life. Women generally include more content that refers to other people and relationships in their narratives than do men (e.g., Grysman et al 2016; Karlsson et al 2019). This begins early in development; when mothers reminisce with their preschool children, they are more likely to include social and relational content than fathers, both about the child's experiences and about their own experiences, such as stories of when they were children (Buckner and Fivush 2000; Fiese and Skillman 2000). By middle childhood, girls include substantially more information about other people and relationships in their narratives than do boys (Buckner and Fivush 1998; Fivush et al 2007).

Finally, a focus on communal themes can also be expressed through emotional language. Although emotions are complex dynamic interactions among physiological, neural, cognitive and sociocultural components (Adolphs and Anders 2018; Barrett et al 2007; Sander et al 2018), emotions must be conceptualised as interpersonal as well as intrapersonal (Campos et al 2011). How individuals narrate their emotional experiences to and with others helps shape particular ways of understanding those experiences and what they mean over time (Fivush and Grysman 2019). Our relationships with others are shaped by the ways in which we understand our emotional experiences together, and extensive research has found that women's narratives include more emotion than men's (e.g., Bauer et al 2003; Bohanek and Fivush 2010; Grysman 2018; Manns et al 2018).

\section{Explicit and implicit gendered narratives}

We have shown that both master narratives and narrative performance differ by gender. We emphasise that master narratives about gender present explicit narrative frameworks for how to perform gender in the world, whereas much of the process of telling narratives remains a more implicit expression of 'doing' gender in the world. Master narratives are subject to sociohistorical and cultural change as stereotypes about gender evolve. But we argue that the implicit performance of gender through narratives is deeply embedded in human experience. There are at least three reasons to suggest that implicit aspects of gendered narration is ubiquitous. First, narrators (at least adolescents) tell narratives from the gendered perspective of the protagonist. When the protagonist is themselves, 
adolescent boys tell autonomous, agentic narratives with little emotion or elaboration, but when they tell about their mothers' personal experiences, the stories are relationally oriented, emotionally expressive and elaborated (Zaman and Fivush 2011). This may simply be the way the story was told to them, but it underscores that boys hear these stories, can tell stories in these more 'female gendered' ways, but choose not to when they are telling their own story - they are choosing to tell a male gendered narrative about themselves, essentially performing gender through narrating in particular ways (see also Way 2011). Similarly, when asked to tell the story of their own birth, clearly not an event that they actually remember, but a family story that they have been told, adolescent girls tell birth stories filled with emotion and relationships, whereas adolescent boys tell bare bone facts (Andrews et al 2015).

Second, when emerging adults self-report on their autobiographical memories, which requires an explicit judgment about the memory, we do not see any gender differences in level of detail or emotion attributed to that memory. But when then asked to narrate the memory, gender differences are apparent, with women telling more detailed and emotionally expressive narratives than men, again suggesting that this may reflect a way of performing gender that is deeply embedded in the telling of narratives. In further support of this, self-ascribed gender identity moderates self-report of personal memories, but it does not affect narratives, again suggesting that performing gender through narrative is deeply implicit and embedded regardless of self-ascribed gender identity (Grysman et al 2017).

Finally, listeners expect and reward gendered narratives. In one example, whether readers of narratives assessed a narrator to be male or female was predicted by the amount of emotional and affiliative language in it (Grysman 2020). Listeners' expectations positively reinforce the narrator when gender typical consistent but may lead to confusion or even opprobrium when it is not, ultimately increasing gendered content of personal narratives. What results is a gendered expectation of how an event narrative is structured in order to be shared. Through modelling, enculturation and expectations by others, women come to perform gendered narratives that are elaborated, relational and emotionally expressive, whereas men come to perform gendered narratives that are less so.

\section{Narratives construct gender/gender constructs narrative}

Research indicates that there are both explicit master narratives of gender that are culturally shared and provide a backdrop against which individual life stories are told, and that there are implicit ways of narrating that express gendered ways of being in the world. However, how and why these differences exist remains elusive. We argue, from evolutionary, psychological and feminist theoretical perspectives, that the relationship between narrative and gender is fundamental to human meaning-making. Gender is an ontological way of understanding the world that shapes the very process and content of narrative meaning-making.

From an evolutionary perspective, language, and more specifically stories, was critical to our adaptation and survival as a group-living species. Sociality and group bonding allowed our ancestral forbearers to engage in fundamentally new forms of behaviour that led to cultural flourishing (Byrne and Bates 2007; Donald 1993), and sharing stories was a critical part of creating a shared world-view and a shared group history that undergirds enduring alliances and commitments among group members (Boyd 2018). These benefits of narration are not gender-specific, as communication and group bonding are integral for all members of a group-living species. But one of the main advantages of a group-living species is division of labour, and, perhaps especially in our ancestral past, 
this division of labour falls along biological sex and reproductive work (Buss and Schmitt 2011; Wood and Eagly 2012). By creating specific roles and responsibilities that follow biological division of reproductive work, certain types of traits and interactions become associated with one sex or the other, creating a more culturally defined understanding of gender that extends beyond biological sex (Wood and Eagly 2012). These gendered divisions of labour and gendered perceptions of traits and dispositions thus become deeply embedded in the way individuals experience the world. Because women do the work of pregnancy, childbirth and early childcare due to biological necessity, women become associated with more relationship-oriented, communal and emotional interactions and traits.

In fact, although some gender stereotypes have shifted over the last several decades to currently perceiving women as equally or more intelligent and competent than men, many aspects of gender stereotypes have remained remarkably consistent, including stereotypes about gender roles, occupations and characteristics such as communality and emotionality (Eagly et al 2020; Haines et al 2016; Lockenhöff et al 2014). These stereotypes also continue to infuse media. Reviewing several recent meta-analyses, Ward and Grower (2020) conclude that men are portrayed more frequently, and as more aggressive, in media than women. Women, in contrast, are portrayed as primarily interested in appearance and are set within the home more often than men. In terms of social media, using a common web-based search engine, Otterbacher et al (2017) searched for images of 'person' and found that images of men were retrieved twice as often as images of women. Furthermore, when 'person' was modified by agentic adjectives (e.g., rational, intelligent) this difference increased, but when 'person' was modified by warm adjectives (e.g., emotional, relational), images of women were retrieved significantly more often than images of men. Perhaps most disturbing they also found a backlash effect, such that when women were portrayed as agentic, they were also portrayed in a negative way. These findings emphasise the pervasiveness of these gender stereotypes even in the face of sociohistorical change, and suggest that these stereotypes may also be pervasive in how individuals construct their own life stories. We emphasise that these differences are not biologically essential, but rather that biological sex predisposes certain forms of behaviour in the world that are then constructed and re-constructed across generations through narratives that are both defining of, and defined by, gender. The conjunction of the need to form enduring alliances, the emergence of narrative as a primary way to do so, and female reproductive work, converge on females becoming the carriers of particular forms of narrative skills and practices that differ by gender. From this perspective, narratives construct female gender along themes of communion and enduring relationships, and gender constructs narrative as a process of building intimacy and emotional attachments.

Second, from a psychological perspective, narratives are fundamental to how humans understand, share and remember lived experience (Bruner 1991). From the moment of birth, infants are surrounded by stories and are expected to participate in storytelling as ways of making sense of the world (Nelson and Fivush 2004). Similarly, gender is foundational to human life. In fact, Martin and Slepian (2020) recently argued that the distinction between agency and communion, prominent in social, developmental and personality psychology by different names (Abele et al 2008), is, at root, a representation of gender. Whereas constructions and meanings of agency and communion are developmentally and culturally variable, all cultures share certain basic representations of gender. In their words,

'This gender role bifurcation has evolved for human survival both in biological necessity (procreation) and gender role functionality (division of labor). The network of 
associations people have for what is masculine and what is feminine (i.e., the gender schema) is a primary lens through which they understand the social world around them, being the first feature they notice about another person (with-out having other information on hand or some specific goal in mind). From learning another person's gender, a broad set of interrelated traits, assumptions, and expectations come to mind.' (Martin and Slepian, p. 11)

Again, we underscore that this is not necessarily an essentialist perspective. Although evolution and biology may set certain boundary conditions on human meaning-making, sociohistorical and cultural influences are equally prominent. Still, the extant research indicates that gender and narrative infiltrate our ways of creating meaning. Our narratives are infused with gendered influences while simultaneously coming to shape the ways in which we view gender through various social and cognitive processes.

Third, from a feminist perspective, narratives can be conceptualised within a framework of voice and silence (Fivush 2004, 2010). Feminist theories of voice and silence dovetail with both evolutionary and psychological theories of meaning-making. Essentially, those in power are allowed to voice, or define, the master narratives in certain ways, while silencing other narratives. Yet, paradoxically, voice or power also allows one to be silent whereas lack of power forces one to explain one's position in the world, and this requires a narrative. Whereas those in power need only voice the narrative from their own perspective, those who are oppressed, those on the margins, must engage in double consciousness, a concept that emerged from critical race theory (Itzigsohn and Brown 2015). Because they are structurally on the outside, marginalised people must see the world both from their own perspective on the margin, as well as the world as constructed from the centre, in order to survive. This leads to marginalised groups having to better understand the intentions, motivations and emotions of those in power. Thus narrative, especially narrative that focuses on multiple perspectives through emotional and relational language, becomes a form of consciousness for women in ways that it is not for men. From this perspective, narratives construct gender as a form of voice, and gender constructs narrative as a form of double consciousness focused on the emotions, intentions and relationships of multiple participants.

\section{Conclusion}

By examining how culturally canonical master narratives and everyday narrative performance explicitly and implicitly construct, and are constructed by, gender, we have shown that gendered identities are created through narrative processes. Moving beyond stereotypes of gender, a narrative approach provides a framework for understanding how gender is created along temporally unfolding narrative dimensions of emotion and communion, and how gender underlies narrative processing along these same dimensions, in an ongoing dialectical relation. Evolutionary, psychological and feminist theory converge on the idea that narratives are constructed within deeply embedded gendered ways of being in the world. Both narrative and gender unfold in mutually constituted ways across both individual and cultural time.

Our approach necessitates looking at the process of narration as it unfolds in everyday life and in multiple contexts. To better appreciate the dialectical relation between gender and narrative, future research should focus on conversational interactions around past experiences and on deeper qualitative analysis of how gendered identities and master narratives provide the ground from which personal narratives emerge. Gendered master narratives pervade the conversations we have at the level of content, context and form, and examining all these elements will be necessary to achieve a deep empirical 
understanding of them. By examining varied contexts of narrating varied content in varied relationships, researchers can provide a fuller description of the range of gendered narration and the ways it builds identity.

Funding. The authors declare that there is no funding for this manuscript and have no competing interests. We further state that, as this is a theoretical piece, there is no data to be made available.

\section{References}

Abbot HP (2008) The Cambridge Introduction to Narrative. Cambridge, MA: Cambridge University Press.

Abele AE, Cuddy AJ, Judd CM and Yzerbyt VY (2008) Fundamental dimensions of social judgment. European Journal of Social Psychology 38, 1063-1065.

Adams S, Kuebli J, Boyle P and Fivush R (1995) Gender differences in parent-child conversations about past emotions: A longitudinal investigation. Sex Roles 5, 33309-33323.

Adolphs R and Andler D (2018) Investigating emotions as functional states distinct from feelings. Emotion Review 10(3), 191-201.

Andrews J, Zaman W, Merrill N, Duke M and Fivush R (2015) Gender differences in adolescent birth narratives. Journal of Applied Research in Memory and Cognition 4(4), 356-362.

Arendell T (2000) Conceiving and investigating motherhood: The decade's scholarship. Journal of Marriage and Family 62(4), 1192-1207.

Ashburn-Nardo L (2017) Parenthood as a moral imperative? Moral outrage and the stigmatization of voluntarily childfree women and men. Sex Roles 76(5), 393-401.

Bakan D (1966) The duality of human existence: An essay on psychology and religion. Rand Mcnally.

Barrett LF, Mesquita B, Ochsner KN and Gross JJ (2007) The experience of emotion. Annual Review of Psychology 58, 373-403.

Bauer PJ, Stennes L and Haight JC (2003) Representation of the inner self in autobiography: Women's and men's use of internal state language in personal narratives. Memory 11, 27-42.

Bischoping K (1993) Gender differences in conversation topics: 1922-1990. Sex Roles 28, 1-18.

Bluck S and Alea N (2002) Exploring the functions of autobiographical memory: Why do I remember the autumn? In Webster JD and Haight BK (eds), Critical Advances in Reminiscence Work. New York, NY: Springer Publishing Company, 61-75.

Bluck S and Alea N (2009) Thinking and talking about the past: Why remember? Applied Cognitive Psychology 23, 1089-1104.

Bohanek JG and Fivush R (2010) Personal narratives, well-being, and gender in adolescence. Cognitive Development 25, 368-379.

Bohanek J, Fivush R, Zaman W, Thomas-Lepore C, Merchant S and Duke M (2009) Narrative interaction in family dinnertime interactions. Merrill-Palmer Quarterly 55, 488-515.

Boyd B (2018) The evolution of stories: From mimesis to language, from fact to fiction. Wiley Interdisciplinary Reviews: Cognitive Science 9(1), e1444.

Boytos AS, Costabile KA, Austin AB and Short KA (2020) Feminism, gender, and agentic and communal themes in narrative identity. Sex Roles 83(1), 54-63.

Breen AV, McLean KC, Cairney K and McAdams DP (2017) Movies, books, and identity: Exploring the narrative ecology of the self. Qualitative Psychology 4(3), 243.

Bruner J (1991) The narrative construction of reality. Critical Inquiry 18, 1-21.

Buckner JP and Fivush R (1998) Gender and self in children's autobiographical narratives. Applied Cognitive Psychology 12(4), 407-429.

Buckner JP and Fivush IV R (2000) Gendered themes in family reminiscing. Memory 8(6), 401-412.

Burleson BR (2003) The experience and effects of emotional support: What the study of cultural and gender differences can tell us about close relationships, emotion, and interpersonal communication. Personal Relationships 10(1), 1-23.

Buss DM and Schmitt DP (2011) Evolutionary psychology and feminism. Sex Roles 64(9-10), 768.

Butkowski CP, Dixon TL, Weeks KR and Smith MA (2020) Quantifying the feminine self (ie): Gender display and social media feedback in young women's Instagram selfies. New Media \& Society 22(5), 817-837.

Byrne RW and Bates LA (2007) Sociality, evolution and cognition. Current Biology 17(16), R714-R723.

Campos JJ, Walle EA, Dahl A and Main A (2011) Reconceptualizing emotion regulation. Emotion Review 3(1), 26-35.

Carr A (1998) Michael White's narrative therapy. Contemporary Family Therapy 20(4), 485-503. 
Compère L, Charron S, Gallarda T, Rari E, Lion S, Nys M, Anssens A, Coussinoux S, Machefaux S, Oppenheim C and Piolino P (2021) Gender identity better than sex explains individual differences in episodic and semantic components of autobiographical memory: An fMRI study. NeuroImage 225, 117507.

Darwin H (2017) Doing gender beyond the binary: A virtual ethnography. Symbolic Interaction 40(3), 317-334.

Donald M (1993) Origins of the Modern Mind: Three Stages in the Evolution of Culture and Cognition. Harvard University Press.

Döring N, Reif A and Poeschl S (2016) How gender-stereotypical are selfies? A content analysis and comparison with magazine adverts. Computers in Human Behavior 55, 955-962.

Eagly AH, Nater C, Miller DI, Kaufmann M and Sczesny S (2020) Gender stereotypes have changed: A crosstemporal metaanalysis of US public opinion polls from 1946 to 2018. American Psychologist 75(3), 301.

Ellemers N (2018) Gender stereotypes. Annual Review of Psychology 69, 275-298.

Endendijk JJ, Derks B and Mesman J (2018) Does parenthood change implicit gender-role stereotypes and behaviors? Journal of Marriage and Family 80(1), 61-79.

Fiese BH and Skillman G (2000) Gender differences in family stories: Moderating influence of parent gender role and child gender. Sex Roles 43(5), 267-283.

Fivush R (2004) Voice and silence: A feminist model of autobiographical memory. In Lucariello J, Hudson JA, Fivush R and Bauer PJ (eds), The Development of the Mediated Mind: Sociolcultural Context and Cognitive Development. Mahwah, NJ: Erlbaum, 79-100.

Fivush R (2010) Speaking silence: The social construction of silence in autobiographical and cultural narratives. Memory 18(2), 88-98.

Fivush R and Grysman A (2019) Emotion and gender in personal narratives. In Pritzker SE, Fenigsen J and Wilce JM (eds), The Routledge Handbook of Language and Emotion. New York: Routledge, 344-359.

Fivush R, Marin K, Crawford M, Reynolds M and Brewin CR (2007) Children's narratives and well-being. Cognition and Emotion 21(7), 1414-1434.

Goodall H (2012) Media's influence on gender stereotypes. Media Asia 39(3), 160-163.

Goodman N (1978) Ways of Worldmaking, vol 51. Cambridge, MA: Hackett Publishing.

Gosling J (2018) Gender fluidity reflected in contemporary society. Jung Journal 12(3), 75-79.

Gotlib A (2016) "But you would be the best mother": Unwomen, counterstories, and the motherhood mandate. Journal of Bioethical Inquiry 13(2), 327-347.

Grysman A (2018) Gender and gender typicality in autobiographical memory: A replication and extension. Memory 26(2), 238-250.

Grysman A (2020) Narrative characteristics of autobiographical memory predict expectations of narrator gender. Memory 28(8), 968-983.

Grysman A and Hudson JA (2013) Gender differences in autobiographical memory: Developmental and methodological considerations. Developmental Review 33(3), 239-272.

Grysman A, Fivush R, Merrill N and Graci M (2016) The influence of gender and gender typicality on autobiographical memory across event types and age groups. Memory \& Cognition 44(6), 856-868.

Grysman A, Merrill N and Fivush R (2017) Emotion, gender, and gender typical identity in autobiographical memory. Memory 25(3), 289-297.

Haines EL, Deaux K and Lofaro N (2016) The times they are a-changing... or are they not? A comparison of gender stereotypes, 1983-2014. Psychology of Women Quarterly 40(3), 353-363.

Hammack PL (2011) Narrative and the politics of meaning. Narrative Inquiry 21(2), 311-318.

Hammack PL, Thompson EM and Pilecki A (2009) Configurations of identity among sexual minority youth: Context, desire, and narrative. Journal of Youth and Adolescence 38(7), 867-883.

Harbus A (2011) Exposure to life-writing as an impact on autobiographical memory. Memory Studies 4(2), 206-220.

Holmes J (1992) Women's talk in public contexts. Discourse \& Society 3(2), 131-150.

Itzigsohn J and Brown K (2015) Sociology and the theory of double consciousness: WEB Du Bois's phenomenology of racialized subjectivity. Du Bois Review: Social Science Research on Race 12(2), 231-248.

Karlsson KP, Sikström S, Jönsson FU, Sendén MG and Willander J (2019) Gender differences in autobiographical memory: Females latently express communality more than do males. Journal of Cognitive Psychology 31(7), 651-664.

Kerrick MR and Henry RL (2017) "Totally in love": Evidence of a master narrative for how new mothers should feel about their babies. Sex Roles 76(1-2), 1-16.

Labov W (1982) Speech actions and reaction in personal narrative. In Tannen D (ed), Analyzing Discourse: Text and Talk. Washington, DC: Georgetown University Press, 217-247.

Leaper C and Ayres MM (2007) A meta-analytic review of gender variations in adults' language use: Talkativeness, affiliative speech, and assertive speech. Personality and Social Psychology Review 11, 328-363. 
Löckenhoff CE, Chan W, McCrae RR, De Fruyt F, Jussim L, De Bolle M, Costa PT, Sutin JAR, Realo A, Allik J, Nakazato K, Shimonaka Y, Hřebíčková M, Graf S, Yik M, Ficková E, Brunner-Sciarra M, de Figueora NL, Schmidt V and Terracciano A (2014) Gender stereotypes of personality: Universal and accurate? Journal of Cross-Cultural Psychology 45(5), 675-694.

MacGeorge EL, Graves AR, Feng B, Gillihan SJ and Burleson BR (2004) The myth of gender cultures: Similarities outweigh differences in men's and women's provision of and responses to supportive communication. Sex Roles 50, 143-175.

Manns JR, Varga NL, Trimper JB and Bauer PJ (2018) Cortical dynamics of emotional autobiographical memory retrieval differ between women and men. Neuropsychologia 110, 197-207.

Martela F and Steger MF (2016) The three meanings of meaning in life: Distinguishing coherence, purpose, and significance. The Journal of Positive Psychology 11(5), 531-545.

Martin AE and Slepian ML (2020) The primacy of gender: Gendered cognition underlies the big two dimensions of social cognition. Perspectives on Psychological Science, 1745691620904961. (published online).

McAdams DP (1992) Unity and purpose in human lives: The emergence of identity as a life story. In Zucker RA, Rabin AI, Aronoff J and Frank SJ (eds), Personality Structure in the Life Course. New York, NY: Springer, 323-375.

Mcadams DP (2001) The psychology of life stories. Review of General Psychology 5(2), 100-122.

McAdams DP (2004) The redemptive self: Narrative identity in America today. In Beike DR, Lampinen JM and Behrend DA (eds), The Self and Memory. New York: Psychology Press, 95-116.

McAdams DP (2019) "First we invented stories, then they changed us": The Evolution of Narrative Identity. Evolutionary Studies in Imaginative Culture 3(1), 1-18.

McLean KC and Breen A (2015) Selves in a world of stories during emerging adulthood. In The Oxford Handbook of Emerging Adulthood. Oxford: Oxford Library of Psychology, Oxford University Press, pp. 385-400.

McLean KC and Syed M (2015) Personal, master, and alternative narratives: An integrative framework for understanding identity development in context. Human Development 58(6), 318-349.

McLean KC, Shucard H and Syed M (2017) Applying the master narrative framework to gender identity development in emerging adulthood. Emerging Adulthood 5(2), 93-105.

McLean KC, Lilgendahl JP, Fordham C, Alpert E, Marsden E, Szymanowski K and McAdams DP (2018) Identity development in cultural context: The role of deviating from master narratives. Journal of Personality 86(4), 631-651.

Merrill N and Fivush R (2016) Intergenerational narratives and identity across development. Developmental Review 40, 72-92.

Merrill N, Gallo E and Fivush R (2015) Gender differences in family dinnertime conversations. Discourse Processes 52(7), 533-558.

Miller T (2005) Making Sense of Motherhood: A Narrative Approach. New York: Cambridge University Press.

Monteagudo JG (2011) Jerome Bruner and the challenges of the narrative turn: Then and now. Narrative Inquiry 21(2), 295-302.

Nelson K and Fivush R (2004) The emergence of autobiographical memory: A social cultural developmental theory. Psychological Review 111(2), 486.

Newman ML, Groom CJ, Handelman LD and Pennebaker JW (2008) Gender differences in language use: An analysis of 14,000 text sample. Discourse Processes 45, 211-236.

Niedzwienska A (2003) Gender differences in vivid memories. Sex Roles 49, 321-331.

Otterbacher J, Bates J and Clough P (2017) Competent men and warm women: Gender stereotypes and backlash in image search results. In Proceedings of the 2017 CHI Conference on Human Factors in Computing Systems, 6620-6631.

Ottsen CL and Berntsen D (2014) The cultural life script of Qatar and across cultures: Effects of gender and religion. Memory 22(4), 390-407.

Park G, Yaden DB, Schwartz HA, Kern ML, Eichstaedt JC, Kosinski M, Stillwell D, Ungar LH and Seligman ME (2016) Women are warmer but no less assertive than men: Gender and language on Facebook. PLoS ONE 11(5), e0155885.

Pasupathi M, McLean KC and Weeks T (2009) To tell or not to tell: Disclosure and the narrative self. Journal of Personality 77(1), 89-124.

Payne E and Smith MJ (2016) Gender policing. In Rodriguez NM (ed.), Critical Concepts in Queer Studies and Education. New York: Palgrave Macmillan, 127-136.

Ricoeur P (1980) Narrative time. Critical Inquiry 7(1), 169-190.

Rime B (2007) The social sharing of emotion as an interface between individual and collective processes in the construction of emotional climate. Journal of Social Issues 63, 307-322.

Rogers LO (2020) "I'm kind of a feminist": Using master narratives to analyze gender identity in middle childhood. Child Development 91(1), 179-196. 
Salisu MA and Dacus JD (2021) Living in a paradox: How older single and widowed black women understand their sexuality. Journal of Gerontological Social Work 64(3), 303-333.

Sander D, Grandjean D and Scherer KR (2018) An appraisal-driven componential approach to the emotional brain. Emotion Review 10(3), 219-231.

Sarbin TR (1986) The Narrative as a Root Metaphor for Psychology. New York, NY: Praeger Publishers/Greenwood Publishing Group.

Scarborough WJ, Sin R and Risman B (2019) Attitudes and the stalled gender revolution: Egalitarianism, traditionalism, and ambivalence from 1977 through 2016. Gender \& Society 33(2), 173-200.

Scarborough WJ, Sin R and Risman B (2019) Attitudes and the stalled gender revolution: Egalitarianism, traditionalism, and ambivalence from 1977 through 2016. Gender \& Society 33(2), 173-200.

Schwartz HA, Eichstaedt JC, Kern ML, Dziurzynski L, Ramones SM, Agrawal M, Shah A, Kosinski M, Stillwell D, Seligman MEP and Ungar LH (2013) Personality, gender, and age in the language of social media: The openvocabulary approach. PLOS ONE 8(9), e73791.

Tannen D (2003) Gender and family interaction. In Holmes J and Meyerhoff M (eds), The Handbook of Language and Gender. Oxford, UK: Blackwell.

Tao AH and Chen X (2017) A review of the theoretical models of stereotypes. International Journal of Research Studies in Science, Engineering and Technology 4(9), 22-26.

Thorne A and McLean KC (2003) Telling traumatic events in adolescence: A study of master narrative positioning. In Fivush R and Haden CA (eds), Autobiographical Memory and the Construction of a Narrative Self: Developmental and Cultural Perspectives. Mahwah, NJ: Lawrence Erlbaum Associates.

Thorstad R, Fivush R and Graci $\mathbf{M}$ (in prep) Similarity of personal and cultural narratives. Manuscript in preparation.

Van De Mieroop D, Miglbauer M and Chatterjee A (2017) Mobilizing master narratives through categorical narratives and categorical statements when default identities are at stake. Discourse \& Communication 11(2), 179-198.

Vida HD, Udasmoro W and Noviani R (2020) Women's resistance towards "Master Narratives" through female travelers' Instagram. KnE Social Sciences, 22-30.

Walls RT, Sperling RA and Weber KD (2001) Autobiographical memory of school. The Journal of Educational Research 95(2), 116-127.

Ward LM and Grower P (2020) Media and the development of gender role stereotypes. Annual Review of Developmental Psychology 2, 177-199.

Way N (2011) Deep Secrets. Cambridge, MA: Harvard University Press.

West C and Zimmerman DH (1987) Doing gender. Gender \& Society 1(2), 125-151.

Wood W and Eagly AH (2012) Biosocial construction of sex differences and similarities in behavior. In Olson JM and Zanna MP (eds), Advances in Experimental Social Psychology, vol 46. Academic Press, 55-123.

Zaman W and Fivush R (2011) When my mom was a little girl...: Gender differences in adolescents' intergenerational and personal stories. Journal of Research on Adolescence 21(3), 703-716.

Robyn Fivush is the Samuel Candler Dobbs Professor of Psychology and Director of the Institute for the Liberal Arts at Emory University, where she has been on the faculty since 1984. She is a Fellow of APA and APS. She researches the social construction of autobiographical memory and narrative identity.

Azriel Grysman is an Assistant Professor of Psychology at Dickinson College where he has been on faculty since 2019. He researches autobiographical memory and narrative methods therein, focusing on gender differences and conversational patterns of recall.

Cite this article: Fivush R, Grysman A (2022). Narrative and gender as mutually constituted meaning-making systems. Memory, Mind \& Media 1, e2, 1-14. https://doi.org/10.1017/mem.2021.4 